\title{
Consideration of Latent Infections Improves the Prediction of Botrytis Bunch Rot Severity in Vineyards
}

\author{
Giorgia Fedele, ${ }^{1}$ Elisa González-Domínguez, ${ }^{2}$ Laurent Delière, ${ }^{3}$ Ana M. Díez-Navajas, ${ }^{4}$ and Vittorio Rossi ${ }^{1, \dagger}$ \\ ${ }^{1}$ Department of Sustainable Crop Production, Facoltà di Scienze Agrarie, Alimentari e Ambientali, Università Cattolica del Sacro \\ Cuore, Piacenza, Italy \\ ${ }^{2}$ Horta srl, 29122 Piacenza, Italy \\ ${ }^{3}$ SAVE, INRA, Villenave d'Ornon, France \\ ${ }^{4}$ NEIKER-Tecnalia, Centro de Arkaute-ko Zentroa, Vitoria-Gasteiz, Spain
}

\begin{abstract}
The current study validated a mechanistic model for Botrytis cinerea on grapevine with data from 23 independent Botrytis bunch rot (BBR) epidemics (combinations of vineyards $\times$ year) that occurred between 1997 and 2018 in Italy, France, and Spain. The model was operated for each vineyard by using weather data and vine growth stages to anticipate, at any day of the vine-growing season, the disease severity (DS) at harvest (severe, DS $\geq 15 \%$; intermediate, $5<\mathrm{DS}<15 \%$; and mild, DS $\leq 5 \%$ ). To determine the ability of the model to account for latent infections, postharvest incubation assays were also conducted using mature ber-

classification was based on field assessments of BBR severity; when the model was operated to include BBR severity after incubation assays, its ability to correctly predict BBR severity increased from $65 \%$ to $>87 \%$. This result showed that the model correctly accounts for latent infections, which is important because latent infections can substantially increase DS. The model was sensitive and specific, with the false-positive and false-negative proportion of model predictions equal to 0.24 and 0 , respectively. Therefore, the model may be considered a reliable tool for decision-making for BBR control in vineyards.
\end{abstract} ries without symptoms or signs of BBR. The model correctly classified the severity of 15 of 23 epidemics ( $65 \%$ of epidemics) when the
Keywords: Botrytis cinerea, latency, mechanistic model, validation
Botrytis bunch rot (BBR), caused by the fungus Botrytis cinerea Pers. (teleomorph Botryotinia fuckeliana (de Bary) Whetzel), is a serious disease in vineyards (Elmer and Michailides 2007; Williamson et al. 2007). The fungus affects all vine organs, especially clusters, and thereby reduces both the quantity and quality of the harvested grape berries. Crop losses result from damage to inflorescences before flowering, to flowers during flowering, to young berries at fruit set, and to berries during ripening; the latter damage is referred to as bunch rot. Quality is reduced because rotted berries have an altered chemical composition that causes undesirable flavors in wine (Steel et al. 2013).

Botrytis cinerea develops and actively grows as a necrotrophic pathogen and as a saprophyte on different substrates (Elmer and Michailides 2007). The pathogen overwinters on herb debris, bunch and leaf trash, and rotted berries, and large numbers of conidia can be produced on these overwintering sites under a wide range of environmental conditions (Ciliberti et al. 2015a, 2016). The multiple infection pathways occur in two periods: between flowering to young cluster development, and after veraison (Elmer and Michailides 2007). During the first period, conidia infect inflorescences and young berries through three pathways. In pathway I, conidia infect the styles and ovules; in pathway IIa, conidia infect the stamens or petals; and in pathway IIb, conidia infect fruit via fruit pedicels (Elmer and Michailides 2007). These infections can cause either blossom blight or latent infections of berries. During the flowering stage, in pathway III, conidia infect and saprophytically colonize bunch trash (the dead stamens, aborted flowers, aborted berries, calyptras, and tendrils) retained within the developing bunches (Elmer and Michailides 2007). In the early season, infection severity

${ }^{\dagger}$ Corresponding author: V. Rossi; vittorio.rossi@unicatt.it

The author(s) declare no conflict of interest.

Accepted for publication 13 January 2020.

(C) 2020 The American Phytopathological Society increases with hours of wetness at temperatures near $20^{\circ} \mathrm{C}$ (Ciliberti et al. 2015a,b, 2016; Latorre and Rioja 2002; Nair and Allen 1993). During the second period, latent infections may become visible as rotted berries and may contribute to final disease severity (DS) but the contribution of latent infections to final disease remains unclear (Keller et al. 2003; McClellan and Hewitt 1973). In addition, the mycelium colonizing the bunch trash can produce conidia under favorable conditions and, in pathway IV, the conidial accumulation within the developing bunch results in a source of inoculum for new infections of the ripening berries (Elmer and Michailides 2007). In pathway Va, wind-dispersed conidia infect ripening berries (Elmer and Michailides 2007) and, in pathway Vb, the aerial mycelium produced on adjacent infected berries infects ripening berries through berry-toberry contact (González-Domínguez et al. 2015). From veraison to ripening, the risk of infection is highest at temperatures between 15 and $25^{\circ} \mathrm{C}$ and also increases with hours of wetness or high relative humidity (Broome et al. 1995; Ciliberti et al. 2015b; Latorre and Rioja 2002; Nair and Allen 1993; Nair et al. 1988). The appearance of symptoms is also promoted by the increasing susceptibility of berries approaching maturity (Deytieux-Belleau et al. 2009; Hill et al. 1981; Kretschmer et al. 2007; Mundy and Beresford 2007).

In spite of the complexity of the life cycle of the pathogen, the management of the disease is commonly based on a routine calendar application of fungicides at four specific grape growth stages (GS): (i) end of flowering (GS69) (Lorenz et al. 1995), (ii) prebunch closure (GS77), (iii) veraison (GS83), and (iv) before harvest (before GS89). This schedule may result in unnecessary sprays because the applications are preventive and do not take into account the real risk of BBR infections (González-Domínguez et al. 2019a). To predict the disease risk and help growers in deciding whether a fungicide application is needed, GonzálezDomínguez et al. (2015) developed a mechanistic model according to the principles of "systems analysis" (Leffelaar and Ferrari 1989). The model was previously evaluated with data collected from 21 vineyards in Italy and France between 2009 and 2014; according to a discriminant function analysis (DFA), the model correctly classified $81 \%$ of the epidemics (González-Domínguez et al. 2015). 
The validation conducted by González-Domínguez et al. (2015), however, used the same dataset that was used to develop the model. It follows that additional validation is needed using an independent dataset (Rossi et al. 2010). Moreover, the model developed by González-Domínguez et al. (2015) indirectly estimates latent infections considering the risk of infections in the early season but the previous validation was conducted by using only BBR severities at cluster maturity in the vineyard and the ability of the model to account for those infections that are still latent at harvest was not assessed. In the present study, the model was further validated with data from 23 independent BBR epidemics that occurred between 1997 and 2018 in Italy, France, and Spain. Latent infections of mature berries were also assessed to determine the ability of the model to account for latent infections.

\section{Materials and Methods}

Vineyards. Data were collected between 1997 and 2018 from plots not treated for BBR in eight experimental vineyards: three in Italy, three in France, and two in Spain. In total, 23 epidemics (combinations of vineyard and year) were considered (Table 1). Vineyards were cropped with grape varieties susceptible to $B$. cinerea (Table 1 ) and were managed as usual for the viticultural area, with the exception that no fungicides were used to control $B$. cinerea. Weather data were collected using standard electronic weather stations placed along the vineyard borders (with sensors at $1.5 \mathrm{~m}$ above the ground). Temperature $\left({ }^{\circ} \mathrm{C}\right)$, relative humidity $(\%)$, wetness duration (hours), and rainfall (millimeters) were measured hourly.

Field assessments. GS of vines were assessed twice each week from inflorescences clearly visible (GS53) until harvest (GS > 89) according to Lorenz et al. (1995). At full ripening (GS89), BBR disease incidence (DI) and DS were visually assessed on a minimum of 100 random bunches per plot (on at least 20 vines/plot) in at least four replicate plots per vineyard. DI was calculated as the percentage of bunches with BBR, and DS was calculated as the percentage of the bunch surface affected by BBR (Hill et al. 2010).
Incubation assays. In 10 of the 23 epidemics that did not show any BBR symptoms in the field (Table 2), incubation assays were conducted to assess the presence of latent infections in ripening berries. In each epidemic, 100 berries (with their pedicel) that did not show any symptoms or sign of rot were randomly collected just before harvest (GS89). Berries were transported to the laboratory in a cooler and were rinsed under tap water for $3 \mathrm{~min}$, disinfested with two-thirds distilled water and one-third 5\% sodium hypochlorite to remove epiphytic microflora, and finally rinsed again with sterile water. Berries were placed in a metallic box $(20 \times 15 \mathrm{~cm}$, with a wet filter paper on the bottom) over a metallic grid net so that berries did not touch each other or the filter paper. Each of four replicate boxes contained 25 berries. The boxes were sealed in plastic bags to maintain a saturated atmosphere and were incubated at $25^{\circ} \mathrm{C}$ with a 12 -h photoperiod for 7 days. DI was then assessed as the percentage of berries showing typical rotting and $B$. cinerea sporulation; the percentage of the surface of each berry affected by BBR was also evaluated. The average severity was then calculated as sum of DS in single (affected) berries divided by the total number of berries (healthy + affected), and a value of DS after incubation assays was assigned based on the standard area diagram of Hill et al. (2010).

Model structure and running. The model was described by González-Domínguez et al. (2015). In brief, the model begins to operate when grape inflorescences are clearly visible (GS53) and ends at harvest (GS90), with a time step of 1 day. The model assumes that inoculum sources are present in the vineyard and estimates the relative abundance of conidia produced on inoculum sources on any day of the grape-growing season as a function of the rate at which the mycelium grows and saprophytically colonizes the source tissue and produces conidia. The model then assumes that, on any day, mature conidia may disperse and settle on host plant surfaces. The model considers two main infection periods. In the first infection period (between GS53 [inflorescences clearly visible] and GS73 [berries groat-sized, bunches begin to hang]), the model calculates a daily infection risk for infections by conidia on inflorescences and

Table 1. Characteristics of the vineyards and summary of the weather data recorded in the first and second infection periods of Botrytis cinerea considered by the model of González-Domínguez et al. (2015) for Botrytis bunch rot (BBR)

\begin{tabular}{|c|c|c|c|c|c|c|c|c|c|}
\hline \multirow[b]{2}{*}{ Epidemic } & \multirow[b]{2}{*}{ Location $^{\mathbf{a}}$} & \multirow[b]{2}{*}{ Year } & \multirow[b]{2}{*}{ Cultivar } & \multicolumn{3}{|c|}{ First infection period ${ }^{b}$} & \multicolumn{3}{|c|}{ Second infection period ${ }^{\mathrm{c}}$} \\
\hline & & & & $\mathbf{T}\left({ }^{\circ} \mathbf{C}\right)^{d}$ & Rain $(\mathbf{m m})$ & Wetness (h) & $\mathbf{T}\left({ }^{\circ} \mathrm{C}\right)$ & Rain $(\mathbf{m m})$ & Wetness (h) \\
\hline LS-97 & La Sauve (FR) & 1997 & Sauvignon & 17.2 & 147.0 & 334 & 22.4 & 130.5 & 415 \\
\hline LA-02 & Latresne (FR) & 2002 & Sauvignon & 17.2 & 135.2 & 535 & 19.4 & 139.8 & 343 \\
\hline LA-03 & Latresne (FR) & 2003 & Sauvignon & 17.8 & 118.6 & 363 & 24.7 & 65.8 & 175 \\
\hline PA-07 & Pauillac (FR) & 2007 & Merlot & 17.1 & 163.4 & 393 & 19.8 & 128.6 & 347 \\
\hline PA-08 & Pauillac (FR) & 2008 & Merlot & 16.9 & 222.2 & 376 & 20.1 & 152.6 & 374 \\
\hline PA-10 & Pauillac (FR) & 2010 & Merlot & 16.2 & 251.4 & 336 & 19.6 & 152.8 & 273 \\
\hline PA-11 & Pauillac (FR) & 2011 & Merlot & 17.4 & 22.4 & 92 & 20.2 & 154.7 & 199 \\
\hline PA-13 & Pauillac (FR) & 2013 & Merlot & 15.8 & 162.5 & 532 & 18.6 & 101.5 & 663 \\
\hline PA-14 & Pauillac (FR) & 2014 & Merlot & 15.9 & 159.7 & 540 & 20.0 & 72.5 & 625 \\
\hline CA-15 & Castell'Arquato (IT) & 2015 & Merlot & 18.8 & 103.4 & 206 & 26.2 & 66.0 & 85 \\
\hline $\mathrm{CO}-15$ & Cormons (IT) & 2015 & Merlot & 18.9 & 178.2 & 255 & 25.5 & 223.6 & 213 \\
\hline MA-15 & Mandriole (IT) & 2015 & Trebbiano Romagnolo & 19.9 & 109.7 & 338 & 24.7 & 50.9 & 295 \\
\hline PA-15 & Pauillac (FR) & 2015 & Merlot & 16.7 & 114.4 & 461 & 20.3 & 195.8 & 450 \\
\hline CA-16 & Castell'Arquato (IT) & 2016 & Merlot & 16.8 & 273.0 & 178 & 24.4 & 97.4 & 60 \\
\hline $\mathrm{CO}-16$ & Cormons (IT) & 2016 & Merlot & 16.5 & 275.5 & 614 & 24.2 & 108.2 & 181 \\
\hline MA-16 & Mandriole (IT) & 2016 & Trebbiano Romagnolo & 17.1 & 184.2 & 446 & 23.5 & 53.3 & 475 \\
\hline LG-16 & La Guardia (SP) & 2016 & Tempranillo & 17.7 & 30.4 & 58 & 18.9 & 35.8 & 35 \\
\hline ZA-16 & Zalla (SP) & 2016 & Hondarrabi Zuri & 16.2 & 105.0 & 392 & 19.1 & 158.4 & 791 \\
\hline CA-17 & Castell'Arquato (IT) & 2017 & Merlot & 17.4 & 120.2 & 300 & 25.8 & 43.2 & 87 \\
\hline $\mathrm{CO}-17$ & Cormons (IT) & 2017 & Merlot & 16.9 & 155.5 & 430 & 25.0 & 108.8 & 410 \\
\hline MA-17 & Mandriole (IT) & 2017 & Trebbiano Romagnolo & 17.9 & 81.4 & 115 & 24.1 & 70.0 & 170 \\
\hline ZA-17 & Zalla (SP) & 2017 & Hondarrabi Zuri & 15.4 & 192.6 & 813 & 18.2 & 177.8 & 940 \\
\hline CA-18 & Castell'Arquato (IT) & 2018 & Merlot & 18.7 & 153.8 & 485 & 24.9 & 77.8 & 412 \\
\hline
\end{tabular}

\footnotetext{
a Country code: IT = Italy, FR = France, and SP = Spain.

b The first infection period extends from growth stage (GS) 53 (inflorescences clearly visible) to GS73 (berries groat-sized, bunches begin to hang).

c The second infection period extends from GS79 (majority of berries touching) to GS89 (berries are ripe for harvest).

$\mathrm{d} \mathrm{T}=$ average of daily temperatures $\left({ }^{\circ} \mathrm{C}\right)$.
} 
young clusters (pathways I and II) (Elmer and Michailides 2007). In the second infection period (between GS79 [majority of berries touching] and GS89 [berries are ripe for harvest]), the model calculates the daily infection risk on ripening clusters for infections caused by conidia (pathway Va) (Elmer and Michailides 2007) and for berry-to-berry infection by aerial mycelium (pathway Vb) (González-Domínguez et al. 2015). Daily values of infection risk are accumulated over the time of the corresponding infection period, and accumulated values produce new variables (SEV1, SEV2, and SEV3), which contribute to the total risk of infection. The model finally uses SEV1, SEV2, and SEV3 as independent variables in a DFA to classify the epidemics in three groups based on DS at harvest: severe, $(\mathrm{DS} \geq 15 \%)$, intermediate $(5<\mathrm{DS}<15 \%)$, or mild (DS $\leq 5 \%$ ).

For each vineyard, the model was operated using the vineyard's weather data and vine GS to predict, on any day of the vinegrowing season, the epidemic group (severe, intermediate, or mild) at harvest (González-Domínguez et al. 2015).

Data analysis. Observed BBR epidemics were classified into three groups based on DS at harvest in the field and after incubation assays as follows: severe, DS $\geq 15 \%$; intermediate, $5 \leq \mathrm{DS}<15 \%$; and mild, DS $<5 \%$ (Table 2). These observed BBR severities (O) were compared with those predicted by the model $(\mathrm{P})$. A $2 \times 2$ contingency table was then built, in which $\mathrm{P}$ and $\mathrm{O}$ were categorized as either DS $<5 \%$ or DS $\geq 5 \%$ by using three different datasets: (i) the 23 epidemics classified based on the DS in the field and predicted by the model (dataset 1), (ii) the 10 epidemics classified based on the DS after incubation assays and predicted by the model (dataset 2), and (iii) the 23 epidemics classified based on the DS after incubation assays or in the field and predicted by the model (dataset 3) (Table 2).

Predictions were classified as follows: (i) true positive, when the epidemics predicted by the model and observed (in the field or in the incubation assay) were both classified as intermediate or severe (i.e., $\mathrm{DS} \geq 5 \%[\mathrm{P}+, \mathrm{O}+])$; (ii) true negative, when the predicted and observed epidemics were both mild (i.e., DS < 5\% [P-,O-]); (iii) false positive, when the predicted epidemics were intermediate or severe but the observed epidemics were mild $(\mathrm{P}+, \mathrm{O}-)$; and (iv) false negative, when the predicted epidemics were mild but the observed epidemics were intermediate or severe $(\mathrm{P}-, \mathrm{O}+)$. The true-positive proportion (TPP or sensitivity), the true-negative proportion (TNP or specificity), the false-positive proportion (FPP), and the falsenegative proportion (FNP) were then calculated (Madden 2006). The overall accuracy of the predictions was calculated as the ratio between correct and total predictions. Bayesian analyses were run to calculate the following posterior probabilities (Madden 2006; Yuen and Hughes 2002): (i) the probability that the observed epidemic was intermediate or severe when predicted to be intermediate or severe, $\mathrm{P}(\mathrm{P}+\mathrm{|O}+)$; (ii) the probability that the observed epidemic was mild when predicted to be mild, $\mathrm{P}(\mathrm{P}-\mathrm{IO}-)$; (iii) the probability that the observed epidemic was mild when predicted to be intermediate or severe (i.e., the model provided unjustified alarms), $\mathrm{P}(\mathrm{P}+\mathrm{lO}-)$; and (iv) the probability that the observed epidemic was intermediate or severe when predicted to be mild (i.e., the model does not predict real infections), $\mathrm{P}(\mathrm{P}-\mathrm{IO}+)$. These posterior probabilities were compared with the prior probabilities. Prior probabilities were calculated as the proportion of intermediate or severe epidemics $\mathrm{P}(\mathrm{O}+)$ or mild epidemics $\mathrm{P}(\mathrm{O}-)$ relative to the total number of epidemics observed in the field.

\section{Results}

BBR severity observed in the field at maturity ranged from DS = 0 to $52.4 \%$ (Table 2). Of the 23 BBR epidemics, 16 were mild (with average DS $=1.1 \pm 0.5$ ), 1 was intermediate (with DS $=11.6$ ), and 6

Table 2. Incidence and severity of Botrytis bunch rot (BBR) in the field and after the incubation assay, and the classifications of the observed and the predicted epidemics for three datasets ${ }^{\mathrm{a}}$

\begin{tabular}{|c|c|c|c|c|c|c|c|c|}
\hline \multirow[b]{3}{*}{ Epidemic } & \multicolumn{7}{|c|}{ Observed } & \multirow{3}{*}{ Predicted group ${ }^{\mathrm{d}}$} \\
\hline & \multicolumn{3}{|c|}{ Field } & \multicolumn{3}{|c|}{ Incubation assay } & \multirow[b]{2}{*}{ Dataset 3} & \\
\hline & DI $(\%)^{\mathbf{b}}$ & $\operatorname{DS}(\%)^{\mathbf{c}}$ & Dataset 1 & DI $(\%)^{b}$ & $\operatorname{DS}(\%)^{\mathrm{c}}$ & Dataset 2 & & \\
\hline LS-97 & 82.9 & 36.8 & $S$ & $\ldots$ & $\ldots$ & $\ldots$ & $S$ & $S$ \\
\hline LA-02 & 87.3 & 37.1 & S & $\ldots$ & $\ldots$ & $\ldots$ & $\mathrm{S}$ & S \\
\hline LA-03 & 30.8 & 4.7 & M & $\ldots$ & $\ldots$ & $\ldots$ & M & M \\
\hline PA-07 & 16.2 & 1.4 & M & $\ldots$ & $\ldots$ & $\ldots$ & M & S \\
\hline PA-08 & 96.1 & 45.9 & $S$ & $\ldots$ & $\ldots$ & $\ldots$ & $S$ & $S$ \\
\hline PA-10 & 46.9 & 2.6 & M & $\ldots$ & $\ldots$ & $\ldots$ & M & M \\
\hline PA-11 & 30.4 & 4.9 & M & $\ldots$ & $\ldots$ & $\ldots$ & M & M \\
\hline PA-13 & 90.3 & 39.2 & $S$ & $\ldots$ & $\ldots$ & $\ldots$ & S & $\mathrm{S}$ \\
\hline PA-14 & 94.8 & 52.4 & S & $\ldots$ & $\ldots$ & $\ldots$ & $\mathrm{S}$ & $\mathrm{S}$ \\
\hline CA-15 & 0.0 & 0.0 & M & 35.5 & 3.0 & M & $\mathrm{M}$ & M \\
\hline $\mathrm{CO}-15$ & 0.0 & 0.0 & M & 77.5 & 9.0 & I & I & $\mathrm{S}$ \\
\hline MA-15 & 0.0 & 0.0 & M & 50.0 & 10.0 & I & I & I \\
\hline PA-15 & 81.6 & 26.8 & S & $\ldots$ & $\ldots$ & $\ldots$ & S & S \\
\hline CA-16 & 0.0 & 0.0 & M & 14.0 & 3.0 & M & M & M \\
\hline $\mathrm{CO}-16$ & 0.0 & 0.0 & M & 56.0 & 15.0 & S & $S$ & S \\
\hline MA-16 & 0.0 & 0.0 & M & 7.0 & 5.0 & I & I & I \\
\hline LG-16 & 2.4 & 0.1 & M & $\ldots$ & $\ldots$ & $\ldots$ & $\mathrm{M}$ & $\mathrm{M}$ \\
\hline ZA-16 & 55.6 & 4.1 & M & $\ldots$ & $\ldots$ & $\ldots$ & $\mathrm{M}$ & S \\
\hline CA-17 & 0.0 & 0.0 & M & 14.0 & 1.0 & M & $\mathrm{M}$ & $\mathrm{M}$ \\
\hline CO-17 & 0.0 & 0.0 & M & 63.0 & 9.0 & I & I & I \\
\hline MA-17 & 0.0 & 0.0 & M & 36.0 & 2.0 & M & M & M \\
\hline ZA-17 & 82.5 & 11.6 & I & $\ldots$ & $\ldots$ & $\ldots$ & I & $\mathrm{S}$ \\
\hline CA-18 & 0.0 & 0.0 & M & 59.0 & 1.1 & M & M & $\mathrm{S}$ \\
\hline
\end{tabular}

a Dataset 1 considers the 23 epidemics that were classified based on disease severity (DS) assessed only in the field (i.e., without data on disease that developed in the incubation assay), dataset 2 considers the 10 epidemics that were classified based on the DS assessed in the incubation assay (these epidemics had no bunch rot in the field), and dataset 3 considers all 23 epidemics, which were classified based on the DS assessed only in the field (for 13 epidemics) or in the field and also in the incubation assay (for 10 epidemics). Epidemic groups: $\mathrm{S}=$ severe (DS $\geq 15 \%$ ), $\mathrm{I}=$ intermediate (5\% $\leq \mathrm{DS}<15 \%$ ), and $\mathrm{M}=$ mild (DS $<5 \%$ ).

$\mathrm{b}$ Disease incidence (DI) assessed as the percentage of bunches or berries affected by BBR in the field and in the incubation assay, respectively; the incubation assay was conducted only for 10 epidemics.

${ }^{c}$ DS assessed as the percentage of the bunch surface affected by BBR in the field or in the incubation assay.

d Epidemic group predicted by the discriminant function analysis described by González-Domínguez et al. (2015). 
were severe (with average DS $=39.7 \pm 3.6$ ) (Table 2). During the first infection period (i.e., from GS53 [inflorescences clearly visible] to GS73 [berries groat-sized, bunches begin to hang]), the average temperature ranged from 15.8 to $19.9^{\circ} \mathrm{C}$ (Table 1), rain ranged from 22.4 to $275.5 \mathrm{~mm}$, and wetness duration ranged from 58 to $614 \mathrm{~h}$ (Table 1). In the second infection period (i.e., from GS79 [majority of berries touching] to GS89 [berries are ripe for harvest]), average temperatures were higher (from 18.2 to $26.2^{\circ} \mathrm{C}$ ) than in the first infection period, rain ranged from 35.8 and $223.6 \mathrm{~mm}$, and wetness duration ranged from 35 to $940 \mathrm{~h}$ (Table 1).

The daily model outputs for the $23 \mathrm{BBR}$ epidemics are presented in Figure 1 in terms of severity categories (mild, intermediate, or severe). Eight of these epidemics (CA-16, CA-15, CA-17, MA-17, LG16, PA-10, LA-03, and PA-11) were predicted to be mild all season long (Fig. 1). The other epidemics were predicted to be intermediate starting from the second week of May (CA-18, CO-16, CO-17, MA16, MA-15, PA-07, PA-15, LA-02, PA-08, and PA-14) to mid-June (ZA-17 and PA-13), which was between 27 and 2 days before GS69 (i.e., end of flowering; Fig. 1). Seven epidemics were then predicted to be severe (CA-18, PA-07, ZA-16, PA-15, LA-02, and PA-13, PA14) after GS83 (i.e., veraison), between 15 and 44 days before GS 89 (i.e., berries ripe for harvest) (Fig. 1). In epidemics CO-16 and ZA-17, the change from intermediate to severe occurred at GS69, between 112 and 96 days before GS89; in CO-15 and LS-97, the classification jumped from mild to severe (Fig. 1).
When the classifications of BBR epidemics based on field assessments and model outputs were compared (dataset 1), 15 of the $23 \mathrm{ep}$ idemics were correctly classified, so that overall accuracy was 0.65 (Table 3). In the eight misclassifications, observed epidemics were mild but the model classified them as intermediate (three cases) or severe (five cases) (Table 2), so that FPP was 0.50 (Table 3). The model correctly classified mild or severe epidemics in 8 of 16 cases, so that TNP was 0.50 , and all of the observed epidemics were mild, so that TPP was 1 and FPP was 0 (Table 3). Based on the Bayesian analysis, the posterior probability that the model correctly predicted an intermediate or severe epidemic, $\mathrm{P}(\mathrm{P}+\mathrm{lO}+)$, was 0.47 ; the posterior probability that the model correctly predicted a mild epidemic, $\mathrm{P}(\mathrm{P}-\mathrm{-O}-)$, was 1.00 (Table 3).

For the 10 epidemics with no BBR at harvest but which included incubation assays, BBR severity without consideration of incubation assays was nil in the field (as indicated earlier) and, therefore, was classified as mild; based on the model, these epidemics were predicted to be mild in four cases and intermediate or severe in six cases (Table 2), so that overall accuracy was 0.40 . If data from the incubation assays were included (dataset 2), DS ranged 1 to $15 \%$, and the epidemics were classified as mild in five cases and intermediate or severe in five cases (Table 2), so that nine of these epidemics were correctly classified by the model, and the overall accuracy of the model increased to 0.90 (Table 3). The only misclassified epidemic was predicted to be

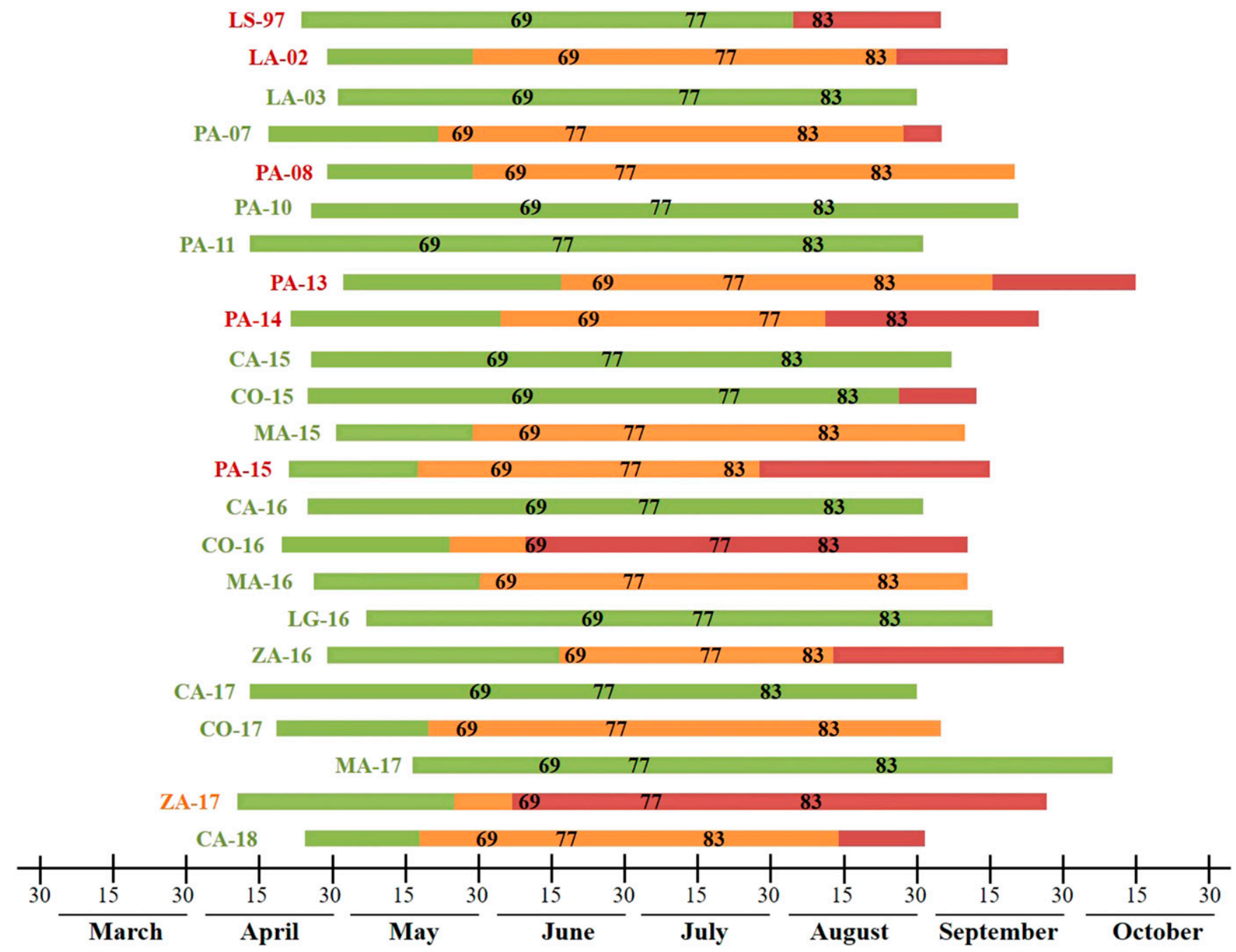

Fig. 1. Classification of 23 Botrytis bunch rot (BBR) epidemics as (left to right) mild, intermediate, or severe based on the model of González-Domínguez et al. (2015), which was operated daily between growth stage (GS) 53 (inflorescences clearly visible) (Lorenz et al. 1995) and GS89 (berries ripe for harvest). The code of the epidemics (e.g., LS-97) on the left of each horizontal bar is also shaded based on the observed BBR disease severity (DS) assessed in the vineyard at harvest as lighter (green), intermediate (orange), and darker (red) when DS $<5 \%, 5 \leq \mathrm{DS}<15 \%$, and DS $\geq 15 \%$, respectively. Numbers inside bars indicate the critical growth stages for fungicide applications: $69=$ end of flowering, $77=$ prebunch closure, and $83=$ veraison. 
severe but was observed to be mild $(\mathrm{DS}=1.1 \%$ ) (i.e., the FPP $=$ 0.20 ) (Table 3). In the Bayesian analysis of dataset 2 , the posterior probability of correctly predicting mild epidemics, $\mathrm{P}(\mathrm{P}-\mathrm{IO}-)$, was 1.00 and of correctly predicting intermediate or severe epidemics, $\mathrm{P}(\mathrm{P}+\mathrm{O}+)$, was 0.83 .

When all 23 observed epidemics were classified based on DS (these classifications included incubation assays for 10 epidemics and field assessment at harvest for 13 epidemics) and compared with model output (dataset 3), 20 of 23 epidemics were correctly classified (i.e., overall accuracy was 0.87 ) (Table 3 ). The three epidemics that were incorrectly classified were mild in the field (with $\mathrm{DS}=0 \%$ ) but were classified as severe by the model; two of these epidemics (PA07 and ZA-16) were only assessed in the field, and only one included an incubation assay (CA-18) (Table 2). The posterior probability of correctly predicting intermediate or severe epidemics, $\mathrm{P}(\mathrm{P}+\mathrm{|O}+)$, was 0.80 , and was higher for dataset 3 than for dataset 1 (which only included field assessment $)(\mathrm{P}(\mathrm{P}+\mathrm{O}+)=0.47)$, while the posterior probability of correctly classifying mild epidemics remained $\mathrm{P}(\mathrm{P}+\mathrm{|O}-)=$ 1.00 (Table 3 ), indicating that the consideration of latent infections in the assessment of BBR severity greatly improved the predictive ability of the model.

\section{Discussion}

As noted above, González-Domínguez et al. (2015) developed a mechanistic model that predicts $B$. cinerea development in grapevines and predicts the severity of BBR at harvest as mild (DS < $5 \%$ ), intermediate $(5 \leq \mathrm{DS}<15 \%)$, or severe (DS $\geq 15 \%)$. As part of the same study, González-Domínguez et al. (2015) cross-validated the model using a dataset composed of 21 epidemics. Although the cross-validation indicated an overall model accuracy of $>80 \%$, the cross-validation used the same data set that was used to develop the model. In the current study, the model was further validated by using an independent dataset based on 23 epidemics (combinations of vineyard and year) in Italy, France, and Spain. The model's ability to predict BBR epidemics as mild, intermediate, or severe was lower when based on the independent dataset rather than on the dataset used by González-Domínguez et al. (2015) (i.e., only 65\% of the epidemics were correctly classified). Specifically, the model (without consideration of latent infections as determined by incubation assays) misclassified $50 \%$ of the mild epidemics (i.e., the epidemics with DS $<5 \%$ ); most of these observed epidemics lacked BBR symptoms at harvest but were predicted to be intermediate or severe by the model. This misclassification refers to false-positive predictions (Madden 2006), which may result in unjustified alarms and, therefore, in unjustified fungicide sprays (Shtienberg 2007). Unjustified sprays should be avoided in order to reduce fungicide costs and fungicide effects on the environment (Epstein 2014) and public health (Alavanja et al. 2004; Verger and Boobis 2013), and in order to reduce the risk that resistance to fungicides develops in $B$. cinerea populations (Fernández-Ortuño et al. 2016; Fillinger and Walker 2016; Leroux 2007).

When the model considered BBR severity based on data obtained both at harvest and after incubation assays, its ability to correctly predict the epidemics as mild, intermediate, or severe increased from 65 to $>87 \%$. In our incubation assays, grape berries without visible symptoms or signs of $B$. cinerea at harvest were kept at a favorable temperature and humidity so that latent infections could become visible; in other words, the consideration of BBR severity after incubation assays for model validation meant the consideration of those latent infections that did not result in BBR symptoms at harvest under field conditions. That latent infections are important in $B$. cinerea epidemiology has been clearly demonstrated (Keller et al. 2003; McClellan and Hewitt 1973; Nair et al. 1995; Pezet and Pont 1984). McClellan and Hewitt (1973) and Pezet and Pont (1984) were the first to report that berries develop latent infections as early as at flowering, and that these infections remain latent (not visible) until berries ripen and, in some cases, are still latent at harvest. Keller et al. (2003) and Nair et al. (1995) found that the majority of rotted berries at harvest had become infected during flowering. The conditions that cause latent infections to result in the visible rotting of berries are not completely understood; several factors may be important, such as meteorological conditions and especially intense rainfall, vineyard and cultivar characteristics, or the presence of wounds or cracks on the berry skin (Elmer and Michailides 2007; Jarvis 1977; Mundy and Beresford 2007; Nair et al. 1988; Nelson 1951).

Table 3. Bayesian statistics of the classification of the 23 Botrytis bunch rot (BBR) epidemics as mild, intermediate, or severe based on field assessments of disease severity (DS) in the field or in the incubation assay (observed) and on the model developed by González-Domínguez et al. (2015) (predicted)

\begin{tabular}{|c|c|c|c|c|c|c|c|c|c|c|c|c|}
\hline \multirow{3}{*}{$\frac{\text { Dataset }^{\mathbf{b}}}{1}$} & \multirow{3}{*}{$\begin{array}{l}\text { Observed }^{\mathbf{c}} \\
\text { Yes }(\mathrm{O}+)\end{array}$} & \multicolumn{2}{|c|}{ Predicted $^{\mathbf{a}}$} & \multirow{3}{*}{$\begin{array}{l}\text { Accuracy }^{\mathbf{d}} \\
0.65\end{array}$} & \multirow{2}{*}{\multicolumn{2}{|c|}{ Likelihood ratio }} & \multirow{2}{*}{\multicolumn{2}{|c|}{$\begin{array}{c}\text { Prior } \\
\text { probability } \\
(\mathbf{P})^{\mathrm{e}}\end{array}$}} & \multirow{2}{*}{\multicolumn{4}{|c|}{ Posterior probability $(\mathbf{P})^{\mathbf{f}}$}} \\
\hline & & \multirow{2}{*}{$\begin{array}{l}\text { Yes }(\mathbf{P + )} \\
7(1.00)^{\mathrm{g}}\end{array}$} & \multirow{2}{*}{$\frac{\text { No }(\mathbf{P}-)}{0(0.00)^{\mathrm{h}}}$} & & & & & & & & & \\
\hline & & & & & $\mathrm{LR}(\mathrm{O}+)$ & 2.00 & $\mathrm{P}(\mathrm{O}+)$ & 0.30 & $\mathrm{P}(\mathrm{P}+\mathrm{O}+)$ & 0.47 & $\mathrm{P}(\mathrm{P}-\mid \mathrm{O}+)$ & 0.00 \\
\hline & No (O-) & $8(0.50)^{\mathrm{i}}$ & $8(0.50)^{\mathrm{j}}$ & $\ldots$ & $\mathrm{LR}(\mathrm{O}-)$ & 0.00 & $\mathrm{P}(\mathrm{O}-)$ & 0.70 & $\mathrm{P}(\mathrm{P}+\mid \mathrm{O}-)$ & 0.53 & $\mathrm{P}(\mathrm{P}-\mid \mathrm{O}-)$ & 1.00 \\
\hline 2 & Yes $(\mathrm{O}+)$ & $5(1.00)$ & $0(0.00)$ & 0.90 & $\mathrm{LR}(\mathrm{O}+)$ & 5.00 & $\mathrm{P}(\mathrm{O}+)$ & 0.50 & $\mathrm{P}(\mathrm{P}+\mid \mathrm{O}+)$ & 0.83 & $\mathrm{P}(\mathrm{P}-\mid \mathrm{O}+)$ & 0.00 \\
\hline & No (O-) & $1(0.20)$ & $4(0.80)$ & $\ldots$ & LR(O-) & 0.00 & $\mathrm{P}(\mathrm{O}-)$ & 0.50 & $\mathrm{P}(\mathrm{P}+\mid \mathrm{O}-)$ & 0.17 & $\mathrm{P}(\mathrm{P}-\mid \mathrm{O}-)$ & 1.00 \\
\hline 3 & Yes $(\mathrm{O}+)$ & $12(1.00)$ & $0(0.00)$ & 0.87 & $\mathrm{LR}(\mathrm{O}+)$ & 3.67 & $\mathrm{P}(\mathrm{O}+)$ & 0.52 & $\mathrm{P}(\mathrm{P}+\mathrm{OO}+)$ & 0.80 & $\mathrm{P}(\mathrm{P}-\mid \mathrm{O}+)$ & 0.00 \\
\hline & No $(\mathrm{O}-)$ & $3(0.27)$ & $8(0.73)$ & $\ldots$ & $\mathrm{LR}(\mathrm{O}-)$ & 0.00 & $\mathrm{P}(\mathrm{O}-)$ & 0.48 & $\mathrm{P}(\mathrm{P}+\mid \mathrm{O}-)$ & 0.20 & $\mathrm{P}(\mathrm{P}-\mid \mathrm{O}-)$ & 1.00 \\
\hline
\end{tabular}

a Membership predicted by the model developed by González-Domínguez et al. (2015). "No" are mild epidemics and "Yes" are intermediate or severe epidemics.

b Dataset 1 considers the 23 epidemics that were classified based on DS assessed only in the field (i.e., without data on disease that developed in the incubation assay) dataset 2 considers the 10 epidemics that were classified based on the DS assessed in the incubation assay (these epidemics had no bunch rot in the field), and dataset 3 considers all 23 epidemics, which were classified based on the DS assessed only in the field (for 13 epidemics) or in the field and also in the incubation assay (for 10 epidemics).

c Observed membership is based on DS of BBR assessed in the field at maturity. "No" are mild epidemics with DS $<5 \%$ and "Yes" are intermediate or severe epidemics with DS $\geq 5 \%$.

d Accuracy: proportion of correct predictions calculated as $(\mathrm{P}+, \mathrm{O}+/ \mathrm{P}-, \mathrm{O}-) /$ total cases.

e Prior probabilities for intermediate or severe $(\mathrm{O}+)$ and mild $(\mathrm{O}-)$ epidemics.

${ }^{f}$ Posterior probabilities: (i) the probability that the observed epidemic was intermediate or severe when predicted to be intermediate or severe, $\mathrm{P}(\mathrm{P}+\mathrm{IO}+)$; (ii) the probability that the observed epidemic was mild when predicted to be mild, $\mathrm{P}(\mathrm{P}-\mathrm{|O}-)$; (iii) the probability that the observed epidemic was mild when predicted to be intermediate or severe (i.e., the model provides unjustified alarms), $\mathrm{P}(\mathrm{P}+\mathrm{|O}-)$; and (iv) the probability that the observed epidemic was intermediate or severe when predicted to be mild (i.e., the model does not predict real infections), $\mathrm{P}(\mathrm{P}-\mathrm{IO}+)$

$\mathrm{g}$ Number of cases; the true-positive proportion (or sensitivity), when the predicted and observed epidemics were both classified as intermediate or severe $(\mathrm{P}+, \mathrm{O}+)$, is shown in parentheses.

h Number of cases; the false-negative proportion, when the predicted epidemics were mild, but the observed epidemics were intermediate or severe ( $\mathrm{P}-, \mathrm{O}+)$, is shown in parentheses.

i Number of cases; the false-positive proportion, when the predicted epidemics were intermediate or severe, but the observed epidemics were mild ( $\mathrm{P}+, \mathrm{O}-$ ), is shown in parentheses.

j Number of cases; the true-negative proportion (or specificity), when both the predicted and observed epidemics were mild ( $\mathrm{P}-\mathrm{O}-\mathrm{O}-$ ), is shown in parentheses 
The improvement of the overall accuracy of the model-based prediction of BBR epidemics from $65 \%$ (based on field data only) to $>87 \%$ (based on field data and incubation assays) showed that the model is able to account for latent infections and, therefore, to correctly represent the complexity of $B$. cinerea epidemiology in vineyards. Specifically, the model correctly predicted 20 of 23 epidemics, with 3 epidemics being classified as mild based on observed data but as severe based on the model. In two of these epidemics (PA-07 and ZA16), DS was assessed in the field only (as 1.4 and $4.1 \%$, respectively), and it is possible that incubation assays, had they been conducted, may have increased the total BBR severity to $>5 \%$ (which would account for the severity in the field plus the severity after incubation assays). Therefore, the FPP of model predictions was very low and the FNP was nil. Based on that, the model can be considered sensitive and specific (Madden 2006), and may be considered a reliable tool for supporting decision making for BBR control in vineyards.

One might argue that a model is not very useful if it advises the need for disease control based on the risk of latent infections even though these infections may remain latent through ripening and harvest (as was the case in 10 epidemics in this research). The control of latent infections, however, is always useful for three reasons. First, latent infections that establish between flowering and fruit set represent an important source of inoculum inside the cluster during ripening, when they initiate the rotting of berries (pathway I, IIa, and IIb of Elmer and Michailides 2007) (Calvo-Garrido et al. 2014); because the reasons why latent infections initiate the rotting of berries during ripening in some cases but not in others are unknown, controlling latent infections is warranted. Second, the advantages of early-season control of $B$. cinerea have been clearly demonstrated (GonzálezDomínguez et al. 2019a,b) and affect other infection pathways such as pathways III (saprophytic colonization of bunch trash) and IV (spore production on bunch trash) of Elmer and Michailides (2007) (CalvoGarrido et al. 2014; Fedele et al. in press), in addition to the latent infection pathways I, IIa, and IIb (Elmer and Michailides 2007). Third, latent infections can alter the chemical properties of berry juices (Steel et al. 2013); in particular, they can increase the contents of glycerol and gluconic acid, which are used as indicators of the negative effects of BBR on grape juice and wines (Nigro and Versari 2008).

In conclusion, the current study validated a mechanistic BBR model recently developed by González-Domínguez et al. (2015). Use of this model could improve BBR management in vineyards by helping farmers schedule fungicides based on the predicted risk of disease. During the season, the model could advise farmers as to whether the current weather conditions are favorable for $B$. cinerea infection and will lead to a final BBR severity $>5 \%$, which is considered a threshold for bunch damage (González-Domínguez et al. 2015). By using the model, farmers would apply fungicides only when the predicted final BBR severity exceeds the threshold; this would prevent the needless application of fungicides. The model is currently available for growers at vite.net, which is a decision support system provided by Horta srl (www.horta-srl.it) for the sustainable management of vineyards (Caffi et al. 2017; Rossi et al. 2012).

\section{Acknowledgments}

G. Fedele conducted this study within the Doctoral School of the Agro-Food System (Agrisystem) at the Università Cattolica del Sacro Cuore, Piacenza, Italy.

\section{Literature Cited}

Alavanja, M. C. R., Hoppin, J. A., and Kamel, F. 2004. Health effects of chronic pesticide exposure: cancer and neurotoxicity. Annu. Rev. Public Health 25: 155-197.

Broome, J., English, J. T., Marois, J. J., Latorre, B. A., and Aviles, J. C. 1995. Development of an infection model for Botrytis bunch rot of grapes based on wetness duration and temperature. Phytopathology 85:97-102.

Caffi, T., Legler, S., González-Domínguez, E., and Rossi, V. 2017. Sustainable management of vineyards: The experience of a large-scale application of a web-based decision support system. In: Proc. 8th Int. Workshop Grapevine Downy and Powdery Mildew, 12.

Calvo-Garrido, C., Usall, J., Viñas, I., Elmer, P. A., Cases, E., and Teixidó, N. 2014. Potential secondary inoculum sources of Botrytis cinerea and their influence on bunch rot development in dry Mediterranean climate vineyards. Pest Manage. Sci. 70:922-930.
Ciliberti, N., Fermaud, M., Languasco, L., and Rossi, V. 2015a. Influence of fungal strain, temperature, and wetness duration on infection of grapevine inflorescences and young berry clusters by Botrytis cinerea. Phytopathology 105:325-333.

Ciliberti, N., Fermaud, M., Roudet, J., Languasco, L., and Rossi, V. 2016. Environmental effects on the production of Botrytis cinerea conidia on different media, grape bunch trash, and mature berries. Aust. J. Grape Wine Res. 22:262-270.

Ciliberti, N., Fermaud, M., Roudet, J., and Rossi, V. 2015b. Environmental conditions affect Botrytis cinerea infection of mature grape berries more than the strain or transposon genotype. Phytopathology 105:1090-1096.

Deytieux-Belleau, C., Geny, L., Roudet, J., Mayet, V., Donèche, B., and Fermaud, M. 2009. Grape berry skin features related to ontogenic resistance to Botrytis cinerea. Eur. J. Plant Pathol. 125:551-563.

Elmer, P. A. G., and Michailides, T. J. 2007. Epidemiology of Botrytis cinerea in orchard and vine crops. Pages 243-272 in: Botrytis: Biology, Pathology and Control. Y. Elad, B. Williamson, P. Tudzynski, and N. Delen, eds. Springer, Dordrecht, The Netherlands.

Epstein, L. 2014. Fifty years since silent spring. Annu. Rev. Phytopathol. 52: 377-402.

Fedele, G., González-Domínguez, E., Si Ammour, M., Languasco, L., and Rossi, V. Reduction of Botrytis cinerea colonization of and sporulation on bunch trash Plant Dis. In press. doi.org/10.1094/PDIS-08-19-1593-RE

Fernández-Ortuño, D., Torés, J. A., Chamorro, M., Pérez-García, A., and de Vicente, A. 2016. Characterization of resistance to six chemical classes of site-specific fungicides registered for gray mold control on strawberry in Spain. Plant Dis. 100:2234-2239.

Fillinger, S., and Walker, A.-S. 2016. Chemical control and resistance management of Botrytis diseases. Pages 189-216 in: Botrytis: The Fungus, the Pathogen and its Management in Agricultural Systems. S. Filinger and Y. Elad, eds. Springer, Dordrecht, The Netherlands.

González-Domínguez, E., Caffi, T., Ciliberti, N., and Rossi, V. 2015. A mechanistic model of Botrytis cinerea on grapevines that includes weather, vine growth stage, and the main infection pathways. PLoS One 10:e0140444.

González-Domínguez, E., Fedele, G., Caffi, T., Delière, L., Sauris, P., Gramaje D., and Rossi, V. 2019a. A network meta-analysis provides new insight into fungicide scheduling for the control of Botrytis cinerea in vineyards. Pest Manage. Sci. 75:324-332.

González-Domínguez, E., Fedele, G., Languasco, L., and Rossi, V. 2019b. Interactions among fungicides applied at different timings for the control of Botrytis bunch rot in grapevine. Crop Prot. 120:30-33.

Hill, G., Stellwaag-Kittler, F., Huth, G., and Schlösser, E. 1981. Resistance of grapes in different developmental stages to Botrytis cinerea. Phytopathol. Z. 102:328-338.

Hill, G. N., Beresford, R. M., and Evans, K. J. 2010. Tools for accurate assessment of Botrytis bunch rot (Botrytis cinerea) on wine grapes. N. Z. Plant Prot. 63:174-181.

Jarvis, W. R. 1977. Botryotinia and Botrytis Species: Taxonomy, Physiology and Pathogenicity. Monograph No. 15. Canada Department of Agriculture, Ontario, Canada.

Keller, M., Viret, O., and Cole, F. M. 2003. Botrytis cinerea infection in grape flowers: Defense reaction, latency, and disease expression. Phytopathology 93:316-322.

Kretschmer, M., Kassemeyer, H. H., and Hahn, M. 2007. Age dependent grey mould susceptibility and tissue-specific defence gene activation of grapevine berry skins after infection by Botrytis cinerea. J. Phytopathol. 155:258-263.

Latorre, B. A., and Rioja, M. 2002. The effect of temperature and relative humidity on conidial germination of Botrytis cinerea. Cienc. Investig. Agrar. 29:67-72.

Leffelaar, P., and Ferrari, T. 1989. Some elements of dynamic simulation. Pages 19-45 in: Simulation and System Management in Crop Protection. R Rabbinge, S. Ward, and H. van Laar, eds. Pudoc Scientific Publishers, Wageningen, The Netherlands.

Leroux, P. 2007. Chemical control of Botrytis and its resistance to chemical fungicides. Pages 195-222 in: Botrytis: Biology, Pathology and Control. Y. Elad, B. Williamson, P. Tudzynski, and N. Delen, eds. Springer, Dordrecht, The Netherlands.

Lorenz, D. H., Eichhorn, K. W., Bleiholder, H., Klose, R., Meier, U., and Weber, E. 1995. Phenological growth stages of the grapevine (Vitis vinifera L. ssp. vinifera) - Codes and descriptions according to the extended $\mathrm{BBCH}$ scale. Aust. J. Grape Wine Res. 1:100-103.

Madden, L. V. 2006. Botanical epidemiology: Some key advances and its continuing role in disease management. Eur. J. Plant Pathol. 115:3-23.

McClellan, W., and Hewitt, W. 1973. Early Botrytis rot of grapes: Time of infection and latency of Botrytis cinerea Pers. in Vitis vinifera L. Phytopathology 63: 1151-1157.

Mundy, D. C., and Beresford, M. R. 2007. Susceptibility of grapes to Botrytis cinerea in relation to berry nitrogen and sugar concentration. N. Z. Plant Prot. 60:123-127.

Nair, N. G., and Allen, R. N. 1993. Infection of grape flowers and berries by Botrytis cinerea as a function of time and temperature. Mycol. Res. 97:1012-1014.

Nair, N. G., Emmet, R. W., and Parker, P. E. 1988. Some factors predisposing grape berries to infection by Botrytis cinerea. N. Z. J. Exp. Agric. 16:257-263.

Nair, N. G., Guilbaud-Oultorfi, S., Barchia, I., and Emmett, R. 1995. Significance of carry over inoculum, flower infection and latency on the incidence of Botrytis cinerea in berries of grapevines at harvest in New South Wales. Aust. J. Exp. Agric. 35:1177-1180. 
Nelson, K. 1951. Factors influencing the infection of table grapes by Botrytis cinerea. Phytopathology 41:319-326.

Nigro, G., and Versari, A. 2008. Metodi rapidi di analisi della qualità dell'uva. Terra Vita 20:56-58.

Pezet, R., and Pont, V. 1984. Botrytis cinerea: Activité antifongique dans les jeunes grappes de Vitis vinifera, varieté Gamay. J. Phytopathol. 111:73-81.

Rossi, V., Caffi, T., and Salinari, F. 2012. Helping farmers face the increasing complexity of decision-making for crop protection. Phytopathol. Mediterr. 51:457-479.

Rossi, V., Giosuè, S., and Caffi, T. 2010. Modelling plant diseases for decision making in crop protection. Pages 241-258 in: Precision Crop Protection: The Challenge and Use of Heterogeneity. E.-C. Oerke, R. Gerhards, G. Menz, and R. A. Sikora, eds. Springer, Dordrecht, The Netherlands.
Shtienberg, D. 2007. Rational management of Botrytis-incited diseases: Integration of control measures and use of warning systems. Pages 335-347 in: Botrytis: Biology, Pathology and Control. Y. Elad, B. Williamson, P. Tudzynski, and N. Delen, eds. Springer, Dordrecht, The Netherlands.

Steel, C. C., Blackman, J. W., and Schmidtke, L. M. 2013. Grapevine bunch rots Impacts on wine composition, quality, and potential procedures for the removal of wine faults. J. Agric. Food Chem. 61:5189-5206.

Verger, P. J., and Boobis, A. R. 2013. Reevaluate pesticides for food security and safety. Science 341:717-718.

Williamson, B., Tudzynski, B., Tudzynski, P., and Van Kan, J. A. L. 2007. Botrytis cinerea: The cause of grey mould disease. Mol. Plant Pathol. 8:561-580.

Yuen, J. E., and Hughes, G. 2002. Bayesian analysis of plant disease prediction. Plant Pathol. 51:407-412. 